\title{
Effects of load on good morning kinematics and EMG activity
}

Andrew D Vigotsky, Erin N Harper, David R Ryan, Bret Contreras

Many strength and conditioning coaches utilize the good morning (GM) to strengthen the hamstrings and spinal erectors. However, little research exists on its electromyography (EMG) activity and kinematics, and how these variables change as a function of load. The purpose of this investigation was to examine how estimated hamstring length, integrated EMG (IEMG) activity of the hamstrings and spinal erectors, and kinematics of the lumbar spine, hip, knee, and ankle are affected by changes in load. Fifteen trained male participants (age $=24.6 \pm 5.3$ years; body mass $=84.7 \pm 11.3 \mathrm{~kg}$; height $=180.9 \pm 6.8$ $\mathrm{cm}$ ) were recruited for this study. Participants performed five sets of the GM, utilizing 50 , $60,70,80$, and $90 \%$ of one-repetition maximum (1RM) in a randomized fashion. IEMG activity of hamstrings and spinal erectors tended to increase with load. Knee flexion increased with load on all trials. Estimated hamstring length decreased with load. However, lumbar flexion, hip flexion, and plantar flexion experienced no remarkable changes between trials. These data provide insight as to how changing the load of the GM affects EMG activity, kinematic variables, and estimated hamstring length. Implications for hamstring injury prevention are discussed. More research is needed for further insight as to how load affects EMG activity and kinematics of other exercises. 
1

2

3

4

$5 \quad{ }^{1}$ Kinesiology Program, School of Nutrition and Health Promotion, College of Health Solutions,

6

$7 \quad{ }^{2}$ School of Sport and Recreation, Auckland University of Technology, Auckland, New Zealand
Andrew David Vigotsky ${ }^{1}$

Erin Nicole Harper, MS ${ }^{1}$

David Russell Ryan, BS ${ }^{1}$

Bret Contreras, $\mathrm{MA}^{2}$
Arizona State University, Phoenix, AZ, United State of America

8 Corresponding Author: Andrew D. Vigotsky

9

10

11

12

\section{INTRODUCTION}

550 N. $3^{\text {rd }}$ St. $\# 401 \mathrm{E}$

Phoenix, AZ 85004

avigotsk@asu.edu

P: 914-584-9750 
14 Training specificity, defined as, "how exercise programs must match functional activities to

15 produce the greatest performance gains" (Morrissey et al. 1995), is a well-known and researched

16 variable of exercise programming (Behm \& Sale 1993; Campos et al. 2002; Graves et al. 1990;

17 Graves et al. 1989; Izquierdo et al. 2002; Morrissey et al. 1995). This means that exercises that

18 better mimic the kinetics and kinematics of the movement attempting to be improved, for

19 example, sprinting, will have a greater and more beneficial carryover. Factors often considered

20 when programming for specificity include range of motion, velocity, and type of contraction, but

21 load and the result of load on a movement are less investigated.

22 Knowing how load affects movement kinematics and electromyography (EMG) activity allows

23 the role of load in resistance training to not only control for intensity, but to also improve

24 specificity, as certain loads may better mimic other movements, especially those in sport. Kellis

25 et al. (2005) found that as Smith-machine barbell load increased for the concentric squat from 7

26 to $70 \%$ of one repetition maximum (1RM), hip, knee, and ankle angles were significantly

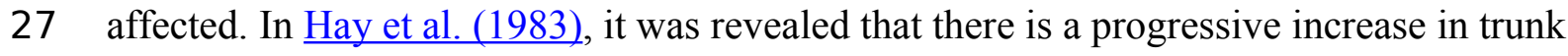

28 inclination, that is, the trunk being more horizontal, at the start of the barbell squat as external

29 load is increased. This change in trunk inclination resulted in the hip extensors assuming

30 markedly more load and the knee extensors markedly less, as determined by resultant joint

31 torques, and so much so that $40 \%$ of participants' four repetition maximum yielded greater and

32 equal resultant knee torques than 80 and 60\%, respectively (Hay et al. 1983). Similar effects were

33 seen in Bryanton et al. (2012), which measured the effects of squat depth and load on relative

34 muscular effort (RME), or, "the muscle force required to perform a task relative to the maximum

35 force the muscle can produce." Knee extensor RME increased with depth, but not load, ankle

36 plantar flexor RME increased with load, but not depth, and hip extensor RME increased with

37 both depth and load. In an isometric bench press, Pinto et al. (2013) found that EMG activity of 
38 the pectoralis major increased from 60 to $80 \%$ of maximum voluntary isometric force production,

39 but the increase from 80 to $90 \%$ was not statistically significant. Aspe \& Swinton (2014)

40 compared the effects of relative loading $(60,75$, and $90 \%$ of three repetition maximum (3RM)) in

41 the back and overhead squat on kinetics and EMG activity. Although investigators did not run

42 statistical analyses on the effects of load, not all mean EMG values of the muscles measured

43 increased linearly with load. It is clear that the relationship between load, kinematics, kinetics,

44 and EMG is not fully understood.

45 The good morning (GM) is a popular exercise in the strength and conditioning community for 46 increasing hamstring and spinal erector strength (Kraemer et al. 1982), but little research exists 47 on its kinematics and EMG activity. The GM is performed by placing a barbell on one's upper 48 trapezius, slightly higher than the barbell positioning in a back squat, with feet about shoulder 49 width apart, and bending forward from the hips until the trunk is approximately parallel with the

50 floor, followed by hip extension to return to starting position (Kraemer et al. 1982). Eccentric

51 hamstring loading has been shown to be beneficial for decreasing the risk of hamstring injury in

52 sport (Askling et al. 2003; Croisier et al. 2008; Heiderscheit et al. 2010; Petersen \& Hölmich

53 2005) and increasing the optimum length of the hamstrings (Brockett et al. 2001). Furthermore, it

54 is recommended that trainees progressively increase the length at which muscles are trained in

55 order to reduce the risk of injury (Malliaropoulos et al. 2012). Therefore, the GM may be an

56 efficacious exercise in preventing hamstring injury.

57 The biomechanics of a GM are similar to that of the stiff leg deadlift (SLDL). Both exercises are

58 used to target the hamstrings muscle group (semitendinosus, semimembranosus, and biceps

59 femoris) via an eccentric muscle action during hip flexion and a concentric muscle action during

60 hip extension (Ebben 2009; McAllister et al. 2014; McGill et al. 2009; Wright et al. 1999). 
61 During an SLDL, the load is held in the hands and lifted off the ground, while a GM has the load

62 resting across the shoulders and is stabilized by the hands. EMG activity of the hamstrings in the

63 GM is similar to that of the SLDL and therefore, the GM may be a good alternative closed kinetic

64 chain movement with a lower quadriceps-to-hamstring ratio to emphasize the hamstrings, or a

65 suitable substitution if gripping the bar is an issue (Ebben 2009).

66 In addition to training for hamstring strengthening, the GM is utilized to target back extensor

67 muscles (Kraemer et al. 1982). Burnett et al. (2002) noted that peak spinal erector forces in the

68 GM $(5929.6 \mathrm{~N})$, while utilizing a typical training load, are comparable to that in the clean, snatch,

69 Romanian deadlift, and bent-over row. Schellenberg et al. (2013) investigated the kinetics and

70 kinematics of the good morning and found maximal segmental flexion angles of 5.3, 75.3, and

$7123.8^{\circ}$ for the knee, hip, and lumbar spine, respectively, and a mean normalized L4/L5 moment of

$722.75 \mathrm{Nm} / \mathrm{BW}$, but the load used was only $25 \%$ of bodyweight. McGill et al. (2009) examined the

73 kinematics and EMG activity during unloaded GM's and found that participants achieved, on

74 average, $55^{\circ}$ of hip flexion and $20^{\circ}$ of lumbar flexion, and the greatest muscular activity was seen

75 in the thoracic erector spinae ( $17 \%$ of maximum voluntary isometric contraction (MVIC)),

76 followed by the lumbar erector spinae ( $\sim 12.5 \%$ MVIC). Biceps femoris activity measured $\sim 5 \%$

77 MVIC. McAllister et al. (2014) reported that erector spinae activity in the GM is similar to that in

78 the Romanian deadlift and prone leg curl, but significantly less than the EMG activity recorded in

79 the glute-ham raise. However, it is difficult to digest and analyze data presented by McAllister et

80 al. (2014), as EMG was not normalized.

81 Despite the GM being a popular exercise in the strength training community, there is a paucity of 82 data on its kinematics and EMG activity (Ebben 2009; McAllister et al. 2014; McGill et al. 2009;

83 Schellenberg et al. 2013). The effects of load during exercise on kinematics and EMG activity 
84 have not been rigorously investigated together. The purpose of this study is to investigate how

85 load affects range of plantar flexion, knee flexion, hip flexion, and lumbar flexion motion, in

86 addition to EMG activity of the thoracic erector spinae, lumbar erector spinae, medial hamstrings,

87 and lateral hamstrings during the GM. Lastly, the approximate length of each hamstring muscle at

88 the bottom of the movement will be calculated using the coefficients provided by Hawkins \&

89 Hull (1989), wherein investigators modeled several lower extremity muscles during various hip,

90 knee, and ankle flexion positions, and created regression equations that can be utilized to obtain

91 muscle lengths based on sagittal plane joint angles.

\section{MATERIALS \& METHODS}

\section{Experimental Approach to the Problem}

94 The purpose of this study was to examine the effects of load on movement kinematics and EMG 95 activity during the GM. During the course of one session, participants warmed up, performed a 96 submaximal 1RM estimation test, and performed one repetition of the GM with varying loads $97(50,60,70,80$, and $90 \% 1 \mathrm{RM})$ in a randomized order, with two minutes rest between each 98 repetition. We hypothesized that as load increases, medial and lateral hamstrings integrated EMG 99 (IEMG) activity would increase, then plateau from 80 to $90 \%$, similar to the findings of Pinto et 100 al. (2013), and lumbar and thoracic erector spinae IEMG activity would increase due to the 101 increase in L5/S1 torque. In order to compensate and decrease hip extension torque, it was also 102 hypothesized that angle of peak ankle plantar flexion would decrease, angle of peak knee flexion 103 would increase, angle of peak lumbar flexion would increase, and angle of peak hip flexion 104 would decrease, and as a result, mean hamstring length would decrease.

\section{Subjects}


106 Fifteen healthy men $(\mathrm{n}=15$; age $=24.6 \pm 5.3$ years; body mass $=84.7 \pm 11.3 \mathrm{~kg}$; height $=180.9$

$107 \pm 6.8 \mathrm{~cm}$ ) with $8.6 \pm 5.5$ years of weightlifting experience, recruited by word of mouth,

108 participated in this study. All participants had weight-trained consistently for at least two years

109 prior to this investigation. All participants were experienced with the GM, having had performed

110 it on a minimum of 12 different occasions over the 12 months prior to testing. All participants

111 were healthy and denied the existence of any current musculoskeletal or neuromuscular injuries,

112 pain, or illnesses; should one have been discovered during testing, that participant was excluded.

113 All participants filled out an Informed Consent and Physical Activity Readiness Questionnaire

114 (PAR-Q) before beginning. Any participant that answered "Yes" to any of the questions on the

115 PAR-Q was excluded. Participants were advised to refrain from resistance training that targeted

116 the lower body or back for 72 hours prior to testing. Using only the barbell on the first warm-up

117 set, participants' form was evaluated to ensure the movement was comfortable and acceptable. If

118 a participant reported pain, discomfort, or failed to perform the movement correctly, that

119 participant was excluded. If, for any reason, a participant could not complete a trial, that trial was

120 excluded; however, if the participant felt comfortable completing them, subsequent trials were

121 not excluded. The study was approved by the Institutional Review Board at Arizona State

122 University (IRB ID: STUDY00000284).

\section{Procedures}

124 Participants warmed up by engaging in five minutes of steady state aerobic exercise on an air

125 resistance bike, an optional self-directed warm-up and/or stretch, and three warm-up sets of GM

126 of 10 repetitions using only the $20 \mathrm{~kg}$ barbell (American College of Sports Medicine 2013).

127 Thereafter, participants were given the option to warm up using additional weight before

128 performing their 1RM estimation test. Using the methods described by Baechle et al. (2008), 
129 participants' 1RM was estimated by performing as many repetitions as possible with what each

130 participant judged to be a moderately heavy load $(8.7 \pm 2.5$ repetitions with $55.5 \pm 25.4 \mathrm{~kg})$.

131 Participants were asked to wear appropriate clothing for access to the EMG sites. Before placing

132 the electrodes on the skin, excess hair was removed with a razor, and skin was cleaned and

133 abraded using an alcohol swab. Disposable, self-adhesive, $\mathrm{Ag} / \mathrm{AgCl}$ pre-gelled, bipolar electrodes

134 (Noraxon Product \#272, Noraxon USA Inc, Scottsdale, AZ), with a diameter of 1 (cm) and an

135 inter-electrode distance of $2 \mathrm{~cm}$, were placed on the muscle bellies, parallel with muscle fibers of

136 the right lateral hamstrings ( $\mathrm{LH})$, right medial hamstrings $(\mathrm{MH})$, right lumbar erector spinae $3 \mathrm{~cm}$

137 lateral to spinous process L3 (LES), and right thoracic erector spinae $5 \mathrm{~cm}$ lateral to spinous

138 process T9 (TES) (Konrad 2005; McGill et al. 2009).

139 Lumbar flexion was calculated by placing $25.4 \mathrm{~mm}$ spherical markers on T11, L1, and S2, and a

$14014.0 \mathrm{~mm}$ marker on the ASIS (Kuo et al. 2009a; Kuo et al. 2009b; Kuo et al. 2009c). In order to

141 calculate hip, knee, and ankle angles, $14.0 \mathrm{~mm}$ markers were placed on the greater trochanter,

142 lateral femoral epicondyle, lateral malleolus, and fifth metatarsophalangeal joint. The four-point

143 angle created by the ASIS, PSIS, greater trochanter, and knee was subtracted from $90^{\circ}$ to find the

144 hip angle, similar to the methods used to calculate lumbar flexion (Figure 1). Peak angles were

145 recorded in the sagittal plane using a $120 \mathrm{~Hz}$ camera (Basler Scout scA640-120, Basler Vision

146 Technologies, USA) and motion analysis software (MaxTRAQ 2D, Innovision Systems Inc.,

147 USA). Utilizing the maximal segmental flexion angles of the hip and knee, hamstring lengths

148 were estimated relative to resting length, as per the equations and coefficients provided by

149 Hawkins \& Hull (1989). 
151 MVIC was taken for the erector spinae by performing a "superman"; in other words, having the

152 participant lay prone and hyperextend their spine with their arms above their head. This position

153 was chosen due to other data suggesting that a prone hyperextension elicits near-maximal erector

154 spinae EMG (Andersson et al. 1996; Callaghan et al. 1998; Liefring et al. 1991), and pilot testing

155 suggested that, in trained individuals, the superman is just as effective as the methods described

156 by Vera-Garcia et al. (2010). Hamstrings MVIC was determined by having the participant lay

157 prone and produce a force against manual resistance at $45^{\circ}$ knee flexion and $0^{\circ}$ hip flexion

158 (Mohamed et al. 2002). In both MVIC positions, participants were instructed to contract "as hard 159 as possible".

160 The barbell was placed on participants' upper trapezius, slightly above the level of the acromion

161 (high bar position); arms were abducted and placed on the bar so the participants' elbows would

162 not block the T11 marker upon descent; participants were instructed to stand how he normally

163 would when performing the GM. Participants' shoes were removed before beginning. Participants

164 performed one repetition of the GM using $50,60,70,80$, and $90 \%$ of estimated $1 \mathrm{RM}$ in a

165 randomized order and were allowed two minutes rest between each repetition. No directions for

166 depth or tempo were provided, as to let the participant perform the GM as he normally would in

167 training.

168 EMG signals of the entire movement (eccentric and concentric), collected at $1500 \mathrm{~Hz}$, were

169 analyzed using MyoResearch 3.4 (Noraxon, USA). A 10-500 Hz bandpass filter was applied to all

170 EMG data. Peak and mean EMG data were rectified, smoothed using root mean square with a

$17150 \mathrm{~ms}$ window, and normalized to peak mean of a $100 \mathrm{~ms}$ window from the MVIC trial. While

172 peak allows for all near-instantaneous increases in muscle activation to be seen, mean is robust to 
173 both movement artifact and time, thus providing a reliable average of EMG activity over the

174 entire movement (Renshaw et al. 2010). EMG data presented as IEMG were rectified then

175 integrated. IEMG was of particular interest because it has been linearly correlated with

176 mechanical work (Bouisset \& Goubel 1971; Bouisset \& Goubel 1973), and is representative of

177 the total electrical potential "spent" to complete the movement. Furthermore, because only one

178 movement is being tested, IEMG is an appropriate measure (Renshaw et al. 2010). Kinematic

179 data includes joint angles at the bottom of the eccentric of the movement, as judged by where

180 maximal hip flexion occurred, which was determined by evaluating movement kinematics in

181 MaxTRAQ (MaxTRAQ 2D, Innovision Systems Inc., USA).

\section{Statistical Analyses}

183 All data were normalized and entered into Stata 13 (StataCorp LP, College Town, TX), wherein

184 one-way analyses of variance (ANOVA) with repeated measures were performed on all EMG and

185 kinematic variables, with load being the independent variable. The normalization process was

186 that described by Loftus \& Masson (1994), as to correct for between-participant variability, thus

187 providing a truer representation of within-participant comparisons across trials. Tukey's HSD

188 post hoc tests were employed on any measure that achieved a main effect. Alpha was set to 0.05

189 for significance. Partial eta-squared effect sizes were calculated and reported, as were their 95\%

190 confidence intervals $(95 \% \mathrm{CI})$. Group means for each trial were used to calculate hamstrings

191 length, utilizing the coefficients presented by Hawkins \& Hull (1989).

\section{RESULTS AND DISCUSSION}

\section{Results}

194 Participants $(\mathrm{n}=15$; age $=24.6 \pm 5.3$ years; body mass $=84.7 \pm 11.3 \mathrm{~kg}$; height $=180.9 \pm 6.8$

$195 \mathrm{~cm}$ ) had $8.6 \pm 5.5$ years of weightlifting experience. During submaximal testing, participants 
196 completed $8.7 \pm 2.5$ repetitions with $55.5 \pm 25.4 \mathrm{~kg}$, and mean estimated $1 \mathrm{RM}$ was $76.0 \pm 24.9$

$197 \mathrm{~kg}$. All but one participant were able to complete every trial; the participant that failed to

198 complete a repetition of $90 \% 1 \mathrm{RM}$ opted not to complete his $80 \% 1 \mathrm{RM}$ trial thereafter; however,

199 his other trials were included. One participant's LH EMG was discarded due to abnormally high

200 readings, indicative of an invalid signal, and one participant's $80 \%$ kinematic data was not

201 included due to corruption of the motion capture video file.

202 [ TABLE 1$]$

203 Mean EMG

204 Main effects were found for MH $\left(p<0.001 ; \mathrm{F}(4,54)=11.77\right.$; partial $\left.\eta^{2}=0.47(0.23,0.58)\right), \mathrm{LH}$

$205\left(\mathrm{p}<0.001 ; \mathrm{F}(4,50)=12.57 ;\right.$ partial $\left.\eta^{2}=0.50(0.26,0.61)\right)$, TES $(\mathrm{p}<0.001 ; \mathrm{F}(4,54)=10.20$;

206 partial $\left.\eta^{2}=0.52(0.29,0.62)\right)$, and LES $\left(p<0.001 ; \mathrm{F}(4,53)=6.08 ;\right.$ partial $\left.\eta^{2}=0.31(0.08,0.45)\right)$

207 mean EMG activity (Table 1).

208 Peak EMG

209 Main effects were found for $\mathrm{MH}\left(\mathrm{p}=0.016 ; \mathrm{F}(4,54)=3.34\right.$; partial $\left.\eta^{2}=0.20(0.01,0.33)\right)$ and

210 TES $\left(\mathrm{p}<0.001 ; \mathrm{F}(4,54)=7.12 ;\right.$ partial $\left.\eta^{2}=0.35(0.11,0.47)\right)$ peak EMG activity, but not LH $(\mathrm{p}$

$211=0.179 ; \mathrm{F}(4,50)=1.64 ;$ partial $\left.\eta^{2}=0.12(0,0.24)\right)$ or LES $\left(\mathrm{p}=0.659 ; \mathrm{F}(4,53)=0.61 ;\right.$ partial $\eta^{2}=$

$2120.04(0,0.12))($ Table 1$)$.

\section{Integrated $E M G$}


214 Main effects were found for MH $\left(\mathrm{p}<0.001 ; \mathrm{F}(4,54)=6.31\right.$; partial $\left.\eta^{2}=0.32(0.09,0.45)\right), \mathrm{LH}(\mathrm{p}$ $215<0.001 ; \mathrm{F}(4,50)=11.99 ;$ partial $\left.\eta^{2}=0.49(0.25,0.60)\right)$, TES $\left(\mathrm{p}<0.001 ; \mathrm{F}(4,54)=8.36 ;\right.$ partial $\eta^{2}$ $216=0.38(0.14,0.51))$, and LES $\left(p<0.037 ; F(4,53)=2.75 ;\right.$ partial $\left.\eta^{2}=0.17(0,0.30)\right)$ IEMG

217 activity (Table 1, Figure 2).

218 [ FIGURE 2 ]

\section{Kinematics}

220 Main effects were found for knee kinematics $\left(p<0.001 ; \mathrm{F}(4,53)=15.07\right.$; partial $\eta^{2}=0.53(0.30$,

$2210.63))$, but not lumbar $\left(\mathrm{p}=0.172 ; \mathrm{F}(4,53)=1.67 ;\right.$ partial $\left.\eta^{2}=0.11(0,0.23)\right)$, hip $(\mathrm{p}=0.715$;

$222 \mathrm{~F}(4,53)=0.53 ;$ partial $\left.\eta^{2}=0.04(0,0.11)\right)$, or ankle $\left(p=0.184 ; \mathrm{F}(4,53)=1.62 ;\right.$ partial $\eta^{2}=0.11$

$223(0,0.22))$ kinematics (Table 2, Figure 3).

224 [ TABLE 2 ]

225 [ FIGURE 3 ]

226 Hamstring length was found to decrease with increases in load. All estimated lengths are greater 227 than those found during sprinting (Table 3).

228 [ TABLE 3$]$

\section{Discussion}

230 The findings of this study provide context as to how EMG and kinematic variables change as a

231 function of load in the GM. Generally, IEMG of MH, LH, TES, and LES increased with load, 
232 except for the 80 and $90 \%$ trials, wherein TES and LES underwent an insignificant decrease

233 (Table 1, Figure 2). The only kinematic variable that appeared to change with load was knee

234 flexion, which increased with load, but not all increases were statistically significant (Table 2,

235 Figure 3). The means of all other kinematic variables did not change more than three degrees and

236 were, therefore, deemed unremarkable, especially considering the variability of the data (Table

237 2). Although the direction of the trends in mean and IEMG were similar, not all IEMG findings

238 displayed similar relative changes in magnitude to the mean EMG data. This is not surprising, as

239 IEMG includes a time component, whereas mean EMG data does not. In other words, a trial with

240 a slightly lower mean may produce greater IEMG if trial duration is longer.

241 Like the findings of Pinto et al. (2013), wherein investigators found that EMG activity plateaued

242 from 80 to $90 \%$ of maximum voluntary isometric force production, participants' mean EMG

243 activity of alleged prime movers (MH and LH) plateaued from 80 to 90\% of 1RM (Table 1).

244 However, significantly more IEMG activity is elicited in the LH at $90 \%$ than at $80 \%$. These data

245 suggest that, in the GM, heavier loads may provide a more potent training stimulus due to both an

246 increase in total muscle activation and torque requirements.

247 The biceps femoris long head (BFLH) and semitendinosus (ST), respectively, are the two most

248 commonly injured muscles of the hamstrings group (Askling et al. 2007; De Smet \& Best 2000),

249 are subjected to the largest amount of stretch during the swing phase of a sprint, and have the

250 largest hip extension moment arms (Chumanov et al. 2006; Thelen et al. 2004). Eccentric

251 hamstring loading has been shown to be beneficial for decreasing the risk of hamstring injury in

252 sport (Askling et al. 2003; Croisier et al. 2008; Heiderscheit et al. 2010; Petersen \& Hölmich

253 2005). In this study, it was found that the BFLH and ST undergo the greatest stretch of all four

254 hamstring muscles, respectively (Table 3), and decrease as a function of load. Additionally, these 
255 data show that the stretch in the GM is greater than the maximum stretch observed during a

256 sprint, which were 1.098, 1.075, and 1.082 for the BFLH, SM, and ST, respectively (Thelen et al.

257 2004). Due to both the eccentric and stretching nature of the GM, it is postulated that the GM

258 may be an effective exercise in preventing hamstring strains through the mechanisms described

259 by Brockett et al. (2001).

260 During the GM, the trunk is to be held stable as movement occurs about the hip joint, thus

261 requiring an isometric action of the spinal erectors. However, these data, and others (McGill et al.

262 2009; Schellenberg et al. 2013), show that movement does occur in the lumbar spine (Table 2).

263 Moreover, the lumbar erectors showed the greatest amount of mean EMG activity when

264 normalized to MVIC (Table 1), although, this could be due to the MVIC position chosen and/or

265 the ability of each participant to maximally contract his erector spinae muscles during MVIC

266 testing. Nevertheless, lumbar extensors show an abnormally large potential for increases in

267 strength with both isotonic and isometric exercise (Graves et al. 1990; Graves et al. 1989; Pollock

268 et al. 1989); therefore, due to the high LES and TES EMG activity in the GM, the GM may be an

269 effective training method for strengthening the erector spinae. However, training studies are

270 needed to elucidate this effect.

271 Although statistical significance was found in these data, one cannot infer clinical significance, as

272 what constitutes a clinically significant difference in EMG activity is not known. It is important

273 to consider that the erector spinae MVIC position chosen in this investigation may not be a true

274 MVIC position for everyone. Due to large inter-participant variability (McGill 1990; $\underline{\text { Vera-Garcia }}$

275 et al. 2010), it is challenging to find an MVIC position that leads to maximal activation for each

276 subject; however, the superman exercise elicited greater EMG activity than the methods

277 described by Vera-Garcia et al. (2010) in trained individuals during pilot testing. In another study, 
278 the superman exercise was only shown to elicit approximately $80 \%$ of MVIC EMG activity

279 (Ekstrom et al. 2008), but this study did not use trained participants, nor were participants

280 encouraged to maximally contract their erector spinae. Thirdly, having participants extend their

281 arms on the barbell might have altered muscular activation. However, the experimenters noticed

282 no change in form by having participants perform the good morning in this manner, but this was

283 not confirmed using kinematic data; all participants were comfortable with this position. As with

284 any dynamic exercise, it is possible the motor units read by the surface EMG electrodes differed

285 not only between loads, but also from MVIC trials. For example, the trials in which the

286 hamstrings experienced greater lengthening, the electrodes may have detected a lesser number of

287 motor units; moreover, it is possible that different motor units were detected during different

288 trials. Additionally, the methods described by Baechle et al. (2008), which assume a linear

289 association between loads lifted and repetitions performed, have not been validated in the GM.

290 Furthermore, participants were not instructed to go to failure on every set, but doing so may have

291 changed the results as this would have controlled for intensity of effort rather than just intensity

292 of load (Steele 2013), resulting in greater activation and more fatigue in all trials. Due to the size

293 principle, EMG activity would theoretically have risen with each repetition until all motor units

294 had been recruited and fatigued (Carpinelli 2008), and light- versus heavy-load research supports

295 this notion (Sundstrup et al. 2012). Lastly, the methods used to calculate hamstring length were

296 not subject specific and only took into account sagittal plane movement.

297 This was the first study to examine both EMG and kinematic data as a function of load. In time,

298 similar studies may show that certain loads may better mimic kinematic and EMG patterns in

299 sport than other loads, or that certain loads emphasize some muscles more than others due to both

300 changes in torque and EMG activity. It is recommended that future research examine these 
301 variables in addition to other kinetic variables, which will improve our understanding of the GM

302 exercise and potentially allow coaches to improve program design strategies.

\section{CONCLUSIONS}

304 The GM is a closed kinetic chain movement that is assumed to involve pure hip extension with a 305 neutral spine. We have shown that the spine does not remain neutral during the GM exercise and 306 in fact moves through flexion and extension. The hips move through a large degree of hip flexion, 307 which requires a high degree of loaded stretch of the hamstring musculature. The hamstrings are 308 of particular interest due to their propensity for injury (Askling et al. 2007; De Smet \& Best

309 2000), and due to the eccentric and stretching nature of the GM, it is postulated that the GM may

310 be an effective movement for the prevention of hamstring injuries. It is clear that EMG activity of

311 the alleged prime movers and knee kinematics are a function of load; therefore, it is

312 recommended that coaches consider these variables within the realms of an athlete's entire

313 program and load the athlete accordingly.

\section{ACKNOWLEDGEMENTS}

315 We would like to thank Bryan Chung for his assistance and expertise, which proved very valuable 316 in the preparation of this paper.

\section{REFERENCES}

Andersson EA, Oddsson LI, Grundstrom H, Nilsson J, and Thorstensson A. 1996. EMG activities of the quadratus lumborum and erector spinae muscles during flexion-relaxation and other motor tasks. Clinical biomechanics 11:392-400.

321

322

323

324

325

326

327

328

Askling C, Karlsson J, and Thorstensson A. 2003. Hamstring injury occurrence in elite soccer players after preseason strength training with eccentric overload. Scandinavian journal of medicine \& science in sports 13:244-250.

Askling CM, Tengvar M, Saartok T, and Thorstensson A. 2007. Acute first-time hamstring strains during high-speed running: a longitudinal study including clinical and magnetic resonance imaging findings. The American journal of sports medicine 35:197-206.

Aspe RR, and Swinton PA. 2014. Electromyographic and Kinetic Comparison of the Back Squat and Overhead Squat. The Journal of Strength \& Conditioning Research. 
Baechle TR, Earle RW, and National Strength \& Conditioning Association (U.S.). 2008. Essentials of strength training and conditioning. Champaign, IL: Human Kinetics.

Behm DG, and Sale DG. 1993. Velocity specificity of resistance training. Sports Med 15:374388.

Bouisset S, and Goubel F. 1971. Interdependence of relations between integrated EMG and diverse biomechanical quantities in normal voluntary movements. Act Nerv Super (Praha) 13:23-31.

Bouisset S, and Goubel F. 1973. Integrated electromyographical activity and muscle work. $J$ Appl Physiol 35:695-702.

Brockett CL, Morgan DL, and Proske U. 2001. Human hamstring muscles adapt to eccentric exercise by changing optimum length. Medicine and science in sports and exercise 33:783-790.

Bryanton MA, Kennedy MD, Carey JP, and Chiu LZ. 2012. Effect of squat depth and barbell load on relative muscular effort in squatting. The Journal of Strength \& Conditioning Research 26:2820-2828.

Burnett A, Netto K, and Beard A. 2002. Back Stress and Assistance Exercises in Weightlifting. Back Stress and Assistance Exercises in Weightlifting.

Callaghan JP, Gunning JL, and McGill SM. 1998. The relationship between lumbar spine load and muscle activity during extensor exercises. Physical therapy 78:8-18.

Campos GE, Luecke TJ, Wendeln HK, Toma K, Hagerman FC, Murray TF, Ragg KE, Ratamess NA, Kraemer WJ, and Staron RS. 2002. Muscular adaptations in response to three different resistance-training regimens: specificity of repetition maximum training zones. Eur J Appl Physiol 88:50-60.

Carpinelli RN. 2008. The size principle and a critical analysis of the unsubstantiated heavier-isbetter recommendation for resistance training. J Exerc Sci Fit.

Chumanov ES, Heiderscheit BC, and Thelen DG. 2006. The effect of speed and influence of individual muscles on hamstring mechanics during the swing phase of sprinting. Journal of biomechanics 40:3555-3562.

Croisier J-LL, Ganteaume S, Binet J, Genty M, and Ferret J-MM. 2008. Strength imbalances and prevention of hamstring injury in professional soccer players: a prospective study. The American journal of sports medicine 36:1469-1475.

De Smet AA, and Best TM. 2000. MR imaging of the distribution and location of acute hamstring injuries in athletes. AJR American journal of roentgenology 174:393-399.

Ebben WP. 2009. Hamstring activation during lower body resistance training exercises. International journal of sports physiology and performance 4:84-96.

Ekstrom RA, Osborn RW, and Hauer PL. 2008. Surface electromyographic analysis of the low back muscles during rehabilitation exercises. The Journal of orthopaedic and sports physical therapy 38:736-745.

Graves JE, Pollock ML, Foster D, Leggett SH, Carpenter DM, Vuoso R, and Jones A. 1990. Effect of training frequency and specificity on isometric lumbar extension strength. Spine (Phila Pa 1976) 15:504-509.

Graves JE, Pollock ML, Jones AE, Colvin AB, and Leggett SH. 1989. Specificity of limited range of motion variable resistance training. Medicine and science in sports and exercise 21:84-89.

Hawkins D, and Hull ML. 1989. A method for determining lower extremity muscle-tendon lengths during flexion/extension movements. Journal of biomechanics 23:487-494.

Hay JG, Andrews JG, Vaughan CL, and Ueya K. 1983. Load, speed and equipment effects in strength-training exercises. Biomechanics VIII-B:939-950.

Heiderscheit BC, Sherry MA, Silder A, Chumanov ES, and Thelen DG. 2010. Hamstring strain injuries: recommendations for diagnosis, rehabilitation, and injury prevention. The Journal of orthopaedic and sports physical therapy 40:67-81. 
380

381

382

383

384

385

386

387

388

389

390

391

392

393

394

395

396

397

398

399

400

401

402

403

404

405

406

407

408

409

410

411

412

413

414

415

416

417

418

419

420

421

422

423

424

425

426

427

428

429

430

431
Izquierdo M, Hakkinen K, Gonzalez-Badillo JJ, Ibanez J, and Gorostiaga EM. 2002. Effects of long-term training specificity on maximal strength and power of the upper and lower extremities in athletes from different sports. Eur J Appl Physiol 87:264-271.

Kellis E, Arambatzi F, and Papadopoulos C. 2005. Effects of load on ground reaction force and lower limb kinematics during concentric squats. Journal of sports sciences 23:1045-1055.

Konrad P. 2005. The ABC of EMG-a practical introduction to kinesiological electromyography. Noraxon INC USA.

Kraemer W, Clark M, and Schmotzer P. 1982. Kinesiology corner: The good morning exercise. Strength \& Conditioning Journal 4:44-44.

Kuo YL, Tully EA, and Galea MP. 2009a. Sagittal spinal posture after Pilates-based exercise in healthy older adults. Spine (Phila Pa 1976) 34:1046-1051.

Kuo YL, Tully EA, and Galea MP. 2009b. Video analysis of sagittal spinal posture in healthy young and older adults. J Manipulative Physiol Ther 32:210-215.

Kuo YL, Tully EA, and Galea MP. 2009c. Video based measurement of sagittal range of spinal motion in young and older adults. Man Ther 14:618-622.

Liefring V, Hinz K, and Seidel W. 1991. Objektivierung der Muskelaktivität bei krankengymnastischen Bewegungsabläufen mit Mehrkanalelektromyographie. Physikalische Medizin.

Loftus GR, and Masson ME. 1994. Using confidence intervals in within-subject designs. Psychonomic bulletin \& review 1:476-490.

Malliaropoulos N, Mendiguchia J, Pehlivanidis H, Papadopoulou S, Valle X, Malliaras P, and Maffulli N. 2012. Hamstring exercises for track and field athletes: injury and exercise biomechanics, and possible implications for exercise selection and primary prevention. British Journal of Sports Medicine.

McAllister MJ, Hammond KG, Schilling BK, Ferreria LC, Reed JP, and Weiss LW. 2014. Muscle activation during various hamstring exercises. The Journal of Strength \& Conditioning Research 28:1573-1580.

McGill SM. 1990. Electromyographic activity of the abdominal and low back musculature during the generation of isometric and dynamic axial trunk torque: implications for lumbar mechanics. Journal of orthopaedic research : official publication of the Orthopaedic Research Society 9:91-103.

McGill SM, Karpowicz A, Fenwick CM, and Brown SH. 2009. Exercises for the torso performed in a standing posture: spine and hip motion and motor patterns and spine load. The Journal of Strength \& Conditioning Research 23:455-464.

Medicine ACoS. 2013. ACSM's guidelines for exercise testing and prescription: Lippincott Williams \& Wilkins.

Mohamed O, Perry J, and Hislop H. 2002. Relationship between wire EMG activity, muscle length, and torque of the hamstrings. Clinical biomechanics 17:569-579.

Morrissey MC, Harman EA, and Johnson MJ. 1995. Resistance training modes: specificity and effectiveness. Medicine and science in sports and exercise 27:648-660.

Petersen J, and Hölmich P. 2005. Evidence based prevention of hamstring injuries in sport. British Journal of Sports Medicine 39:319-323.

Pinto R, Cadore E, Correa C, da Silva B, Alberton C, Lima C, and de Moraes A. 2013. RELATIONSHIP BETWEEN WORKLOAD AND NEUROMUSCULAR ACTIVITY IN THE BENCH PRESS EXERCISE. Med Sport.

Pollock ML, Leggett SH, Graves JE, Jones A, Fulton M, and Cirulli J. 1989. Effect of resistance training on lumbar extension strength. Am J Sports Med 17:624-629.

Renshaw D, Bice MR, Cassidy C, Eldridge JA, Powell, and Douglas W. 2010. A Comparison of Three Computer-based Methods Used to Determine EMG Signal Amplitude. International Journal of Exercise Science 3:1-7.

Schellenberg F, Lindorfer J, List R, Taylor WR, and Lorenzetti S. 2013. Kinetic and kinematic differences between deadlifts and goodmornings. BMC Sports Sci Med Rehabil 5:27. 
432

433

434

435

436

437

438

439

440

441

442

443

444

445

Steele J. 2013. Intensity; in-ten-si-ty; noun. 1. Often used ambiguously within resistance training. 2. Is it time to drop the term altogether? British Journal of Sports Medicine.

Sundstrup E, Jakobsen MD, Andersen CH, Zebis MK, Mortensen OS, and Andersen LL. 2012. Muscle activation strategies during strength training with heavy loading vs. repetitions to failure. The Journal of Strength \& Conditioning Research 26:1897-1903.

Thelen DG, Chumanov ES, Hoerth DM, Best TM, Swanson SC, Li L, Young M, and Heiderscheit BC. 2004. Hamstring muscle kinematics during treadmill sprinting. Medicine and science in sports and exercise 37:108-114.

Vera-Garcia FJ, Moreside JM, and McGill SM. 2010. MVC techniques to normalize trunk muscle EMG in healthy women. Journal of electromyography and kinesiology : official journal of the International Society of Electrophysiological Kinesiology 20:10-16.

Wright GA, DeLong TA, and Gehlsen G. 1999. Electromyographic activity of the hamstrings during performance of the leg curl, stiff-leg deadlift, and back squat movements. The Journal of Strength \& Conditioning Research 13:168-174. 


\section{Table 1 (on next page)}

Mean $(95 \% \mathrm{Cl})$ of measured EMG variables for each load performed.

* Loads sharing a letter are not statistically different $(p>0.05)$. 


\begin{tabular}{|c|c|c|c|c|c|}
\hline & $50 \% 1 \mathrm{RM}$ & $60 \% 1 \mathrm{RM}$ & $70 \% 1 \mathrm{RM}$ & $80 \%$ 1RM & $90 \% 1 \mathrm{RM}$ \\
\hline IEMG MH $\left(\mu V^{*} s\right)$ & $255(205,304)^{A}$ & $309(261,358)^{A B}$ & $370(290,450)^{A B}$ & $398(262,535)^{A B}$ & $492(301,683)^{\mathrm{B}}$ \\
\hline IEMG LH $\left(\mu \mathrm{V}^{*} \mathrm{~s}\right)$ & $201(178,224)^{\mathrm{A}}$ & $189(151,226)^{A}$ & $242(214,270)^{\mathrm{A}}$ & $245(222,269)^{\mathrm{A}}$ & $337(291,382)^{B}$ \\
\hline IEMG TES $\left(\mu V^{*} \mathrm{~s}\right)$ & $253(214,292)^{A}$ & $284(259,309)^{A B}$ & $317(300,333)^{\mathrm{BC}}$ & $358(318,384)^{\mathrm{C}}$ & $357(326,375)^{\mathrm{C}}$ \\
\hline IEMG LES $\left(\mu \mathrm{V}^{*} \mathrm{~s}\right)$ & $373(348,397)^{\mathrm{A}}$ & $401(365,436)^{A B}$ & $415(375,455)^{A B}$ & $496(401,591)^{\mathrm{B}}$ & $474(387,561)^{A B}$ \\
\hline Mean MH (\%MVIC) & $26.2(23.1,29.2)^{A}$ & $28.4(25.4,31.4)^{\mathrm{A}}$ & $34.4(31.4,37.5)^{\mathrm{B}}$ & $37.3(34.1,40.4)^{\mathrm{B}}$ & $39.9(36.8,43.1)^{\mathrm{B}}$ \\
\hline Mean LH (\%MVIC) & $19.5(17.2,21.9)^{\mathrm{A}}$ & $19.3(17.0,21.7)^{\mathrm{AB}}$ & $24.2(21.8,26.6)^{\mathrm{BC}}$ & $26.4(23.9,28.8)^{C D}$ & $30.4(28.0,32.9)^{\mathrm{D}}$ \\
\hline Mean TES (\%MVIC) & $46.4(41.0,51.9)^{\mathrm{A}}$ & $52.2(46.7,57.6)^{\mathrm{AB}}$ & $61.4(56.0,66.8)^{\mathrm{BC}}$ & $69.6(63.9,75.2)^{\mathrm{C}}$ & $66.6(61.0,72.2)^{\mathrm{C}}$ \\
\hline Mean LES (\%MVIC) & $50.8(43.9,58.0)^{\mathrm{A}}$ & $54.9(47.9,61.8)^{\mathrm{A}}$ & $61.5(54.5,68.5)^{\mathrm{AB}}$ & $73.1(65.9,80.4)^{\mathrm{B}}$ & $70.9(63.5,78.4)^{B}$ \\
\hline Peak MH (\%MVIC) & $90.3(80.5,100)^{\mathrm{A}}$ & $94(84,104)^{A B}$ & $113(103,123)^{\mathrm{B}}$ & $101(90.6,111)^{A B}$ & $112(101,122)^{B}$ \\
\hline Peak LH (\%MVIC) & $71.9(64.6,79.1)$ & $77.1(69.9,84.4)$ & $81.0(73.8,88.3)$ & $82.4(74.9,89.9)$ & $85.3(77.8,92.9)$ \\
\hline Peak TES (\%MVIC) & $122(109,135)^{A}$ & $128(115,141)^{A}$ & $145(132,158)^{A B}$ & $158(145,172)^{B}$ & $167(154,181)^{\mathrm{B}}$ \\
\hline Peak LES (\%MVIC) & $142(125,158)$ & $146(130,162)$ & $155(138,173)$ & $157(141,174)$ & $158(141,175)$ \\
\hline
\end{tabular}


Table 2 (on next page)

Mean $(95 \% \mathrm{Cl})$ of joint angle at movement depth for each load performed.

* Loads sharing a letter are not statistically different $(p>0.05)$. 


\begin{tabular}{|c|c|c|c|c|c|}
\hline & $50 \% 1 \mathrm{RM}$ & $60 \% 1 \mathrm{RM}$ & $70 \% 1 \mathrm{RM}$ & $80 \% 1 \mathrm{RM}$ & $90 \% 1 \mathrm{RM}$ \\
\hline Lumbar flexion $\left(^{\circ}\right)$ & $27.5(25.7,29.3)$ & $27.2(25.6,28.7)$ & $25.0(23.0,27.1)$ & $25.0(23.6,26.4)$ & $25.0(22.5,27.5)$ \\
\hline Hip flexion $\left(^{\circ}\right)$ & $75.0(73.6,76.4)$ & $75.3(74.3,76.3)$ & $75.7(74.8,76.5)$ & $75.8(74.5,77.2)$ & $74.7(73.2,76.2)$ \\
\hline Knee flexion $\left({ }^{\circ}\right)$ & $17.1(15.6,18.5)^{\mathrm{A}}$ & $19.1(17.6,20.5)^{\mathrm{AB}}$ & $20.1(18.7,21.5)^{\mathrm{B}}$ & $23.1(21.5,24.6)^{\mathrm{C}}$ & $24.8(23.3,26.3)^{\mathrm{C}}$ \\
\hline Ankle plantar flexion $\left({ }^{\circ}\right)$ & $121.1(120.0,122.3)$ & $120.3(119.6,121.1)$ & $120.2(119.4,121.0)$ & $119.7(119.0,120.5)$ & $119.5(118.1,120.8)$ \\
\hline
\end{tabular}


Table 3(on next page)

Mean peak hamstring lengths normalized to resting hamstring lengths for each load performed.

a Thelen et al. (2004) 


\begin{tabular}{l|rrrrrr}
\hline & Sprint $^{\text {a }}$ & $\mathbf{5 0 \%}$ 1RM & $\mathbf{6 0 \%}$ 1RM & 70\% 1RM & 80\% 1RM & 90\% 1RM \\
\hline Biceps Femoris (LH) & 1.098 & 1.124 & 1.121 & 1.120 & 1.116 & 1.111 \\
Biceps Femoris (SH) & & 0.997 & 0.996 & 0.995 & 0.993 & 0.992 \\
Semitendinosus & 1.082 & 1.126 & 1.123 & 1.123 & 1.117 & 1.112 \\
Semimembranosus & 1.075 & 1.108 & 1.105 & 1.103 & 1.097 & 1.091 \\
\hline
\end{tabular}


1

Marker placement and angle calculations. 


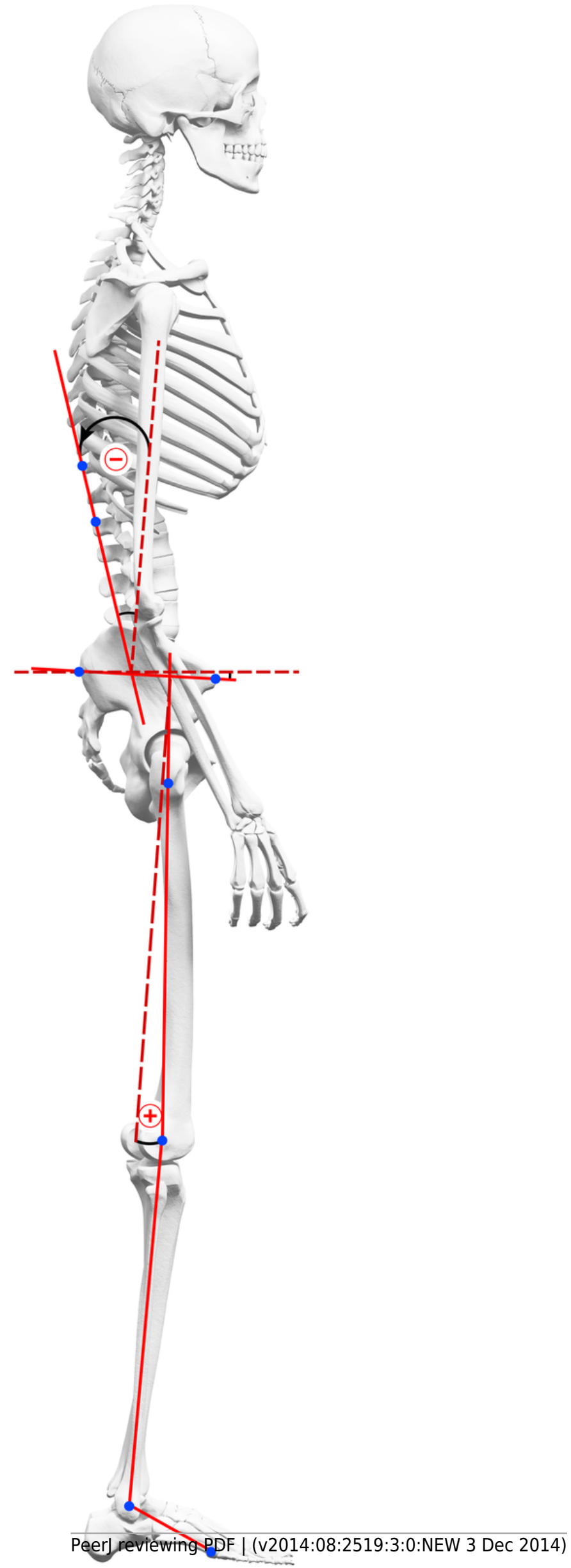


2

IEMG activity versus load.

* Errors bars denote $95 \% \mathrm{Cl}$.

** Loads sharing a letter are not statistically different $(p>0.05)$.
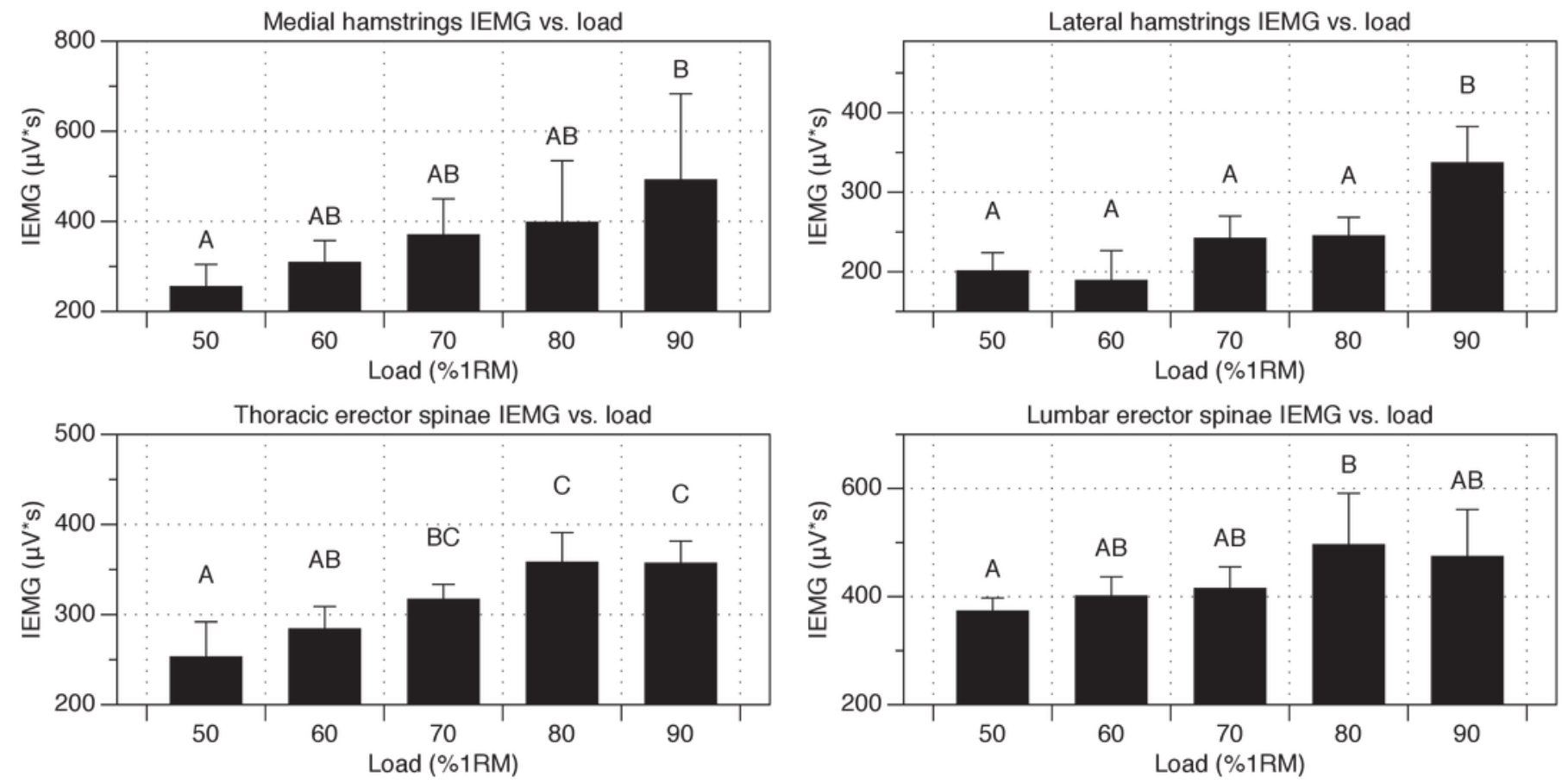
3

Knee kinematics versus load.

* Errors bars denote $95 \% \mathrm{Cl}$.

** Loads sharing a letter are not statistically different $(p>0.05)$.

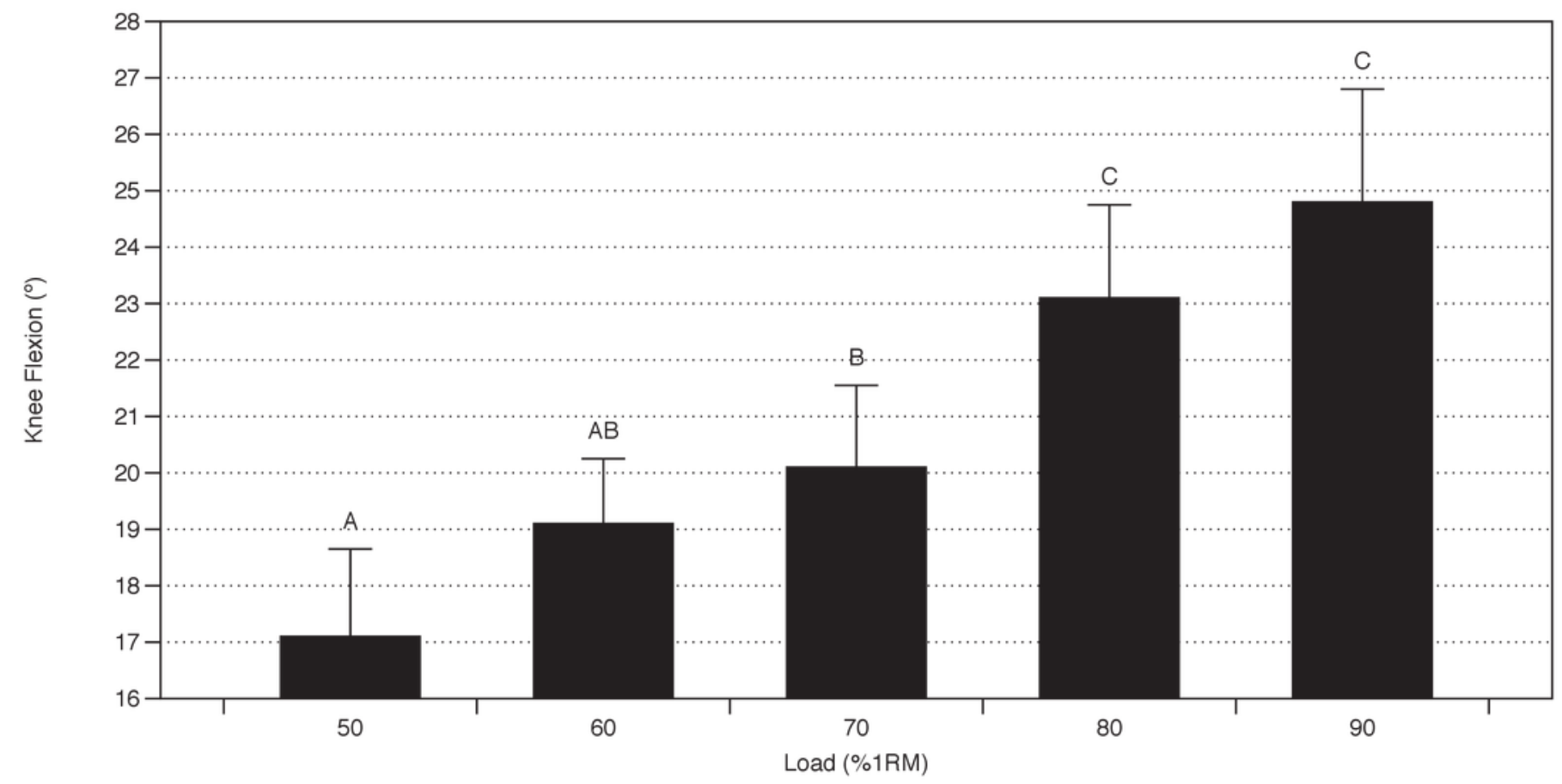

